\title{
Laurence Cox, Buddhism and Ireland - From the Celts to the Counter-Culture and Beyond
}

\section{Catherine Maignant}

\section{(2) OpenEdition}

12 Journals

\section{Édition électronique}

URL : http://journals.openedition.org/etudesirlandaises/4003

DOI : 10.4000/etudesirlandaises.4003

ISSN : 2259-8863

Éditeur

Presses universitaires de Rennes

\section{Édition imprimée}

Date de publication : 20 novembre 2014

Pagination : 192-193

ISBN : 978-2-7535-3559-6

ISSN : 0183-973X

Référence électronique

Catherine Maignant, "Laurence Cox, Buddhism and Ireland - From the Celts to the Counter-Culture and Beyond », Études irlandaises [En ligne], 39-2 | 2014, mis en ligne le 20 novembre 2014, consulté le 19 avril 2019. URL : http://journals.openedition.org/etudesirlandaises/4003; DOI : 10.4000/ etudesirlandaises.4003 
tion, dans lequel le portrait du tueur de l'IRA est jugé complaisant. Harte n'hésite pas non plus à afficher des convictions autant esthétiques qu'idéologiques lorsqu'il condamne A Long Long Way de Sebastian Barry, dans lequel il reproche à l'auteur de susciter la compassion pour les soldats irlandais enrôlés pendant la Première Guerre mondiale, en développant ce qu'il appelle une « esthétique problématique et des aspects polémiques ». En Irlande, l'histoire, la politique et la littérature demeurent inextricablement mêlées.

Sylvie Mıкоwsкi

Laurence Cox, Buddhism and Ireland - From the Celts to the Counter-Culture and Beyond, Sheffield (UK)/Bristol (USA), Equinox, 2013, 413 p., ISBN 978-1908049-30-8.

Buddhism and Ireland propose l'exploration passionnante d'une question peu connue, l'histoire ou plutôt les histoires des interactions entre le bouddhisme et l'Irlande. Laurence Cox est sociologue, mais il offre au lecteur une réflexion interdisciplinaire de grande ampleur, un regard aux facettes multiples indispensable à l'évocation complète d'un sujet aussi complexe en perspective diachronique et synchronique. D'un point de vue théorique global, l'ambition de l'auteur est de montrer que l'on ne peut comprendre les phénomènes décrits que dans la perspective du système-monde. L'Irlande à différentes périodes est envisagée comme l'un des éléments d'espaces interdépendants qui définissent le cadre global de développements multiples. L'histoire du bouddhisme n'est donc pas une, mais plurielle; aucune continuité n'y est décelable, outre celle qui lie entre eux les contextes généraux.

Après un premier chapitre théorique et méthodologique, l'ouvrage est structuré en trois parties, qui recouvrent les trois grands moments du rapport de l'Irlande au bouddhisme. La première va $\mathrm{du} \mathrm{VI}^{\mathrm{e}}$ siècle et des premiers textes qui attestent la connaissance de l'existence de cette religion dans l'île, jusqu'au milieu du XIx ${ }^{e}$ siècle. Cette section constitue la toute première tentative visant mettre en forme une histoire de la réception du bouddhisme en Irlande à la période étudiée. L'auteur y démontre que connaissance ne rime en aucun cas avec adoption et conversion en l'absence de facteurs particuliers inconnus avant le milieu du $\mathrm{XIX}{ }^{\mathrm{e}}$ siècle.

La deuxième partie s'intéresse au siècle qui sépare la décennie suivante des années 1960. L'élément nouveau qui va alors déterminer de nouvelles interactions avec le bouddhisme et les premières conversions est le développement de l'Empire 
britannique en Asie, qu'accompagnent les premières missions chrétiennes, et singulièrement catholiques. Tandis que l'orientalisme et la théosophie connaissent leur heure de gloire en Irlande, les premiers convertis irlandais adoptent le bouddhisme pour se démarquer de l'impérialisme et marquer leur opposition face à l'effort missionnaire. La plupart d'entre eux se fixeront définitivement en Asie, les positions et le mode de vie choisis rendant tout retour socialement impossible dans une Irlande où religion et identité se cristallisent en un idéal social qui exclut toute dissidence.

La dernière période, étudiée dans la troisième partie du volume, se résume à l'ère contemporaine, des années 1960 à nos jours. La contre-culture, le développement du féminisme, la globalisation et, plus récemment, le déclin de l'Eglise catholique en République d'Irlande ont permis à diverses religions alternatives de prendre leur essor. Le bouddhisme, sous des formes diverses (institutionnelle, informelle, créolisée) a bénéficié de ce nouveau contexte et il figure aujourd'hui au $3^{\mathrm{e}}$ ou $4^{\mathrm{e}}$ rang des religions les mieux représentées dans le pays. Laurence Cox distingue clairement le bouddhisme occidental, qui l'intéresse au premier chef, du bouddhisme pratiqué par les immigrants attirés par les succès du Tigre celtique, qui n'a encore pu faire l'objet d'aucune étude ethnographique précise. S'il centre son analyse sur la République, il évoque le cas, bien spécifique, de l'Irlande du Nord et réfléchit aux avenirs possibles. Aujourd'hui, s'afficher comme bouddhiste est devenu possible et l'éloignement de la contre-culture a permis de gagner en respectabilité. De très nombreux centres, dont une liste complète figure dans l'ouvrage, ont ouvert leurs portes et accueillent adeptes et sympathisants. S'il reconnaît que le déclin suit souvent rapidement l'ouverture de tels établissements, Laurence Cox souligne néanmoins le succès très réel du choix d'une identité de moins en moins difficile à assumer, bien qu'elle s'inscrive nettement en opposition par rapport à la tradition irlandaise.

L'ouvrage est excellent et d'une lecture très agréable. Outre une réflexion en contrepoint sur la constitution des identités en Irlande et des dissidences par rapport à ces identités, il propose une galerie de portraits de personnages hauts en couleurs aux destinées aventurières tout à fait extraordinaires, qui ravissent le lecteur. À partir des marges, enfin, il suggère une lecture novatrice des différentes périodes examinées et aborde l'Irlande contemporaine d'une manière susceptible de trouver des développements tout à fait riches dans d'autres domaines que celui de la religion. 